\title{
An Emerging White LED Technology and associated Thermal Issues - A Review
}

\author{
Tauheed ur Rahman ${ }^{1}$, Safdar Raza ${ }^{2 *}$, Mazhar Saeed $^{1}$, Shahzad Jameel ${ }^{1}$ \\ ${ }^{1}$ Department of Electrical Engineering, University College of Engineering \& Technology, Bahauddin Zakariya University, \\ Multan, Pakistan \\ ${ }^{2}$ Department of Electrical Engineering, NFC Institute of Engineering and Technology, Multan, Pakistan. \\ *safdar.raza@nfciet.edu.pk (Corresponding Author)
}

\begin{abstract}
White light emitting diodes (white-LEDs) are the promising light sources of new lighting technology due to their high efficiency, energy saving, long life and environmentally friendly. In this review, different techniques proposed for the development of white-LEDs have been discussed in terms of their performance efficiency and potential usage. The Phosphor based white-LEDs are widely used LEDs, as compared to RGB based white-LEDs, due to their luminous efficacy, service life, display color gamut and the color rendering. Furthermore, thermal issues related to high power white-LEDs have been discussed as it greatly impacts the performance efficiency. To resolve thermal issues, heat sinks having high thermal conductivity are most widely used among others.
\end{abstract}

Keywords- Light-emitting diode (LED); RGB-LEDs; Phosphor; High power white LEDs; Thermal issues.

Date Received 24-08-2019

Date Accepted 25-12-2019

Date Published 31-12-2019

\section{INTRODUCTION}

$\mathrm{G}_{\mathrm{i}}$ etting light by rubbing sticks/stones was common practice in early ages. The initial techniques adopted by humans for indoor lighting were candles and oil lamps [1]. Humphry Davy invented the first arc lamp which was later modified by Foucault. The invention of incandescent lamp and fluorescent lamp has completely changed the trend of lighting [2]. The invention of fluorescent lamp was a big milestone especially for indoor lighting. The development of high-intensity discharge lamps replaced these old technologies; however, some lamp types could not enhance the efficiency more than 70\% [3,4]. The struggle for the efficiency enhancement leads to the invention of LEDs. It has been considered as an encouraging fourth generation light source due to its long life, high luminance, less weight, smaller size, optical efficiency, less power consumption and environmentally friendly [5]. Lifetime of LEDs is 5 times more than fluorescents lamps and 25 times more than incandescent bulbs [6]. LEDs are replacing incandescent and fluorescent lamps due to major factors like absence of mercury and higher efficiency for indoor lighting. About $10.3 \%$ electricity of commercial sector in USA is dedicated to lighting and $6.2 \%$ of residential sector, as estimated in 2018 [7]. If all the traditional white light sources are changed to white-LED, power utilization can be minimized by $1,000 \mathrm{TWh} /$ year [8].

LEDs are not inherently white light source and are developed by different techniques due to their wide applications [9]. White LEDs can be developed using Red-green-blue (RGB) and phosphor coating. Nichia Chemical Industries has developed blue LED using Gallium Nitride (GaN) which has been considered a milestone in the development of white-LED [10]. In this study, different configurations to develop white-LEDs by using blue LED chips are briefly discussed. Thermal stability is a major issue especially in high power LEDs. Furthermore, different thermal models are comprehended along with their drawbacks and solutions in high power LEDs. Heat sinks play a vital role in high power LEDs to dissipate heat to the surroundings.

\section{WHITE-LED TECHNOLOGY}

LED is a semiconductor diode that radiates energy (light) under forward biased condition. The core of LED is a chip having $\mathrm{p}$-side and $\mathrm{n}$-side. The electrical properties of a semiconductor can be changed by introducing impurities by a process called doping. When a semiconductor is doped at different locations with different materials, a junction is formed between two areas of differently doped materials. When the diode is forward biased, electrons from n-type region moves towards p-type region. The emission of photons (light) occurs due to the recombination of holes and electrons [11]. The electrons from the conduction band $\left(E_{c}\right)$ jumps to valence band $\left(E_{v}\right)$ and emit light, as shown in Fig. 1 . In figure $E_{f}$ is the fermi level.

The wavelength of radiation depends on energy band gap $\left(E_{g}\right)$. Planck-Einstein's equation describes this phenomenon by relation 1 [11].

$$
E=h v=h c / \lambda=E_{g}
$$


where $E$ is energy of photon, $h$ indicates the Planck's constant, $v$ is photon frequency, $\lambda$ is wavelength of emitted light and $c$ specify the speed of light.

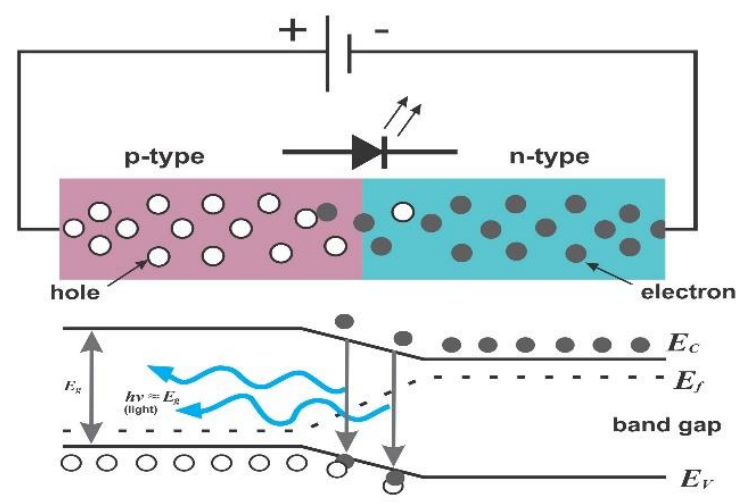

Fig. 1. Light generation principle of LED.

The color of light depends on the energy gap and energy gap governed by semiconductor material. If energy gap increases, the frequency of emitted light increases and, thus, wavelength decreases. LED can emit the electromagnetic radiations in invisible spectrum. [12]. Table I summarizes the different wavelengths and their emitting materials $[12,13]$.

TABLE I : EMITTED COLOR OF LED WITH WAVELENGTH AND MATERIALS

\begin{tabular}{|l|l|l|}
\hline LED light & $\begin{array}{l}\text { Wavelength } \\
(\mathbf{n m})\end{array}$ & Material \\
\hline Infra-Red & $>720$ & $\begin{array}{l}\text { Gallium arsenide (GaAs), } \\
\text { Aluminum gallium arsenide } \\
\text { (AlGaAs). }\end{array}$ \\
\hline Red & $625-720$ & $\begin{array}{l}\text { Gallium phosphide (GaP), } \\
\text { Gallium arsenide phosphide } \\
\text { (GaAsP), Indium gallium } \\
\text { phosphide (InGaP). }\end{array}$ \\
\hline Orange & $600-625$ & $\begin{array}{l}\text { Gallium phosphide (GaP), } \\
\text { Aluminum gallium indium } \\
\text { phosphide (AlGaInP), } \\
\text { Gallium arsenide phosphide } \\
\text { (GaAsP). }\end{array}$ \\
\hline Yellow & $570-600$ & $\begin{array}{l}\text { Gallium phosphide (GaP), } \\
\text { Aluminum gallium indium } \\
\text { phosphide (AlGaInP), } \\
\text { Gallium arsenide phosphide } \\
\text { (GaAsP). nitride (GaN), }\end{array}$ \\
\hline Green & $515-570$ & $\begin{array}{l}\text { Gallium gallium } \\
\text { Aluminum } \\
\text { phosphide (AlGaP). }\end{array}$ \\
\hline Blue & $455-490$ & $\begin{array}{l}\text { Aluminum indium gallium } \\
\text { nitride (AlInGaN), Indium } \\
\text { gallium nitride (InGaN), } \\
\text { Gallium nitride (GaN). }\end{array}$ \\
\hline Ultraviolet & $<390$ & $\begin{array}{l}\text { Indium gallium nitride } \\
\text { (InGaN), Diamond (C), } \\
\text { Aluminum gallium nitride } \\
\text { (AlGaN) }\end{array}$ \\
\hline
\end{tabular}

To operate LED in daily life applications, diversity in LED chips have been proposed, namely conventional, vertical injection and flip chips. In conventional chip, $\mathrm{p}$ and $\mathrm{n}$ electrodes are positioned on top of the LED chip and sapphire is used as a substrate. The electrodes in vertical injection chip are positioned at top and base of the chip, and silicon is used instead of sapphire substrate to enhance thermal conductivity. On contrast with conventional type, it has reduced series resistance and improved power transformation effectiveness [14-16]. Flip chip is an inverted structure of conventional chip having both electrodes at base of the chip and light is radiated from top of the structure which evades light retention by the metal as in the case of conventional chip. Flip chip structure LEDs own better thermal characteristics. Lu et al. [17] presented a thermal analysis on high power flip chip LED. The different chip structures are shown in Fig. 2 where MQW is multiple quantum well.

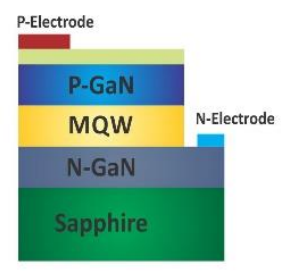

Conventional Chip

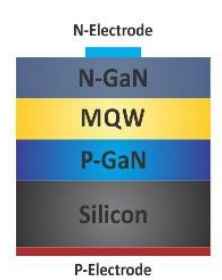

Vertical Injection Chip

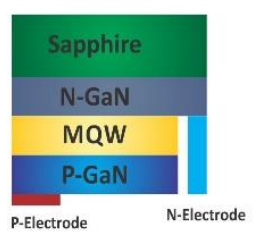

Flip Chip
Fig. 2. Different types of LED chips [18].

White light is the basic requirement in illumination but there is no such LED that emits white light inherently. White light emitting LED (white-LEDs) can be obtained in two ways; 1 ) RGB-LEDs system. 2) Phosphor coating method [19]. WhiteLEDs with phosphor coating method are extensively developed by utilizing blue LED chips and widely used for commercial purposes.

There are few parameters that determine the efficiency of LEDs such as color rendering index (CRI), light extraction efficiency (LEE), color temperature (CT), luminous efficacy [20]. International commission of illumination defines the CRI as the effect of an illuminant on color appearance of the object by conscious or subconscious comparison with its color appearance under a reference illuminant [21]. Color temperature is the temperature of ideal black body that radiates light whose color resembles to given light source [22]. Luminous efficacy is the ratio of luminous flux to input power and measured in $1 \mathrm{~m} / \mathrm{W}$ [23]. Light extraction efficiency (LEE) tells us how much photons generated in active region are escaped into free space [24]. To enhance the productivity of LEDs, many techniques have been introduced and immense research further suggesting the new methods have been recorded.

\section{RGB BASED WHITE-LEDS}

The wavelength of electromagnetic radiations visible to human eye is about $380-770$ nanometers and white light is the mixture of different wavelengths of electromagnetic spectrum 
in the visible portion [25]. It is a well-known verity that white color LED can be produced by blending the three colors; red, green and blue emitting from different LEDs [26,27]. This is the straightforward method. However, this technique requires complex electrical design to control light intensity since blending the correct ratio of these three colors will produce white light. Chromatic diagram can be used to represent it and CIE 1931 coordinate axis is the most commonly use chromatic diagram [28]. The diagram shows all the colors visible to average person. If some two-color points are chosen on chromaticity diagram, then any color that lie in straight line joining these two points can be formed by blending these two colors. Similarly, by combining coordinates of three different colors, it is possible to produce all colors that lie inside triangle formed by source points [29]. The ideal white point (W.P) on CIE chart has coordinates $(0.33,0.33)$ [30]. The CIE 1931 chromaticity diagram with ideal white point is shown in Fig. 3.

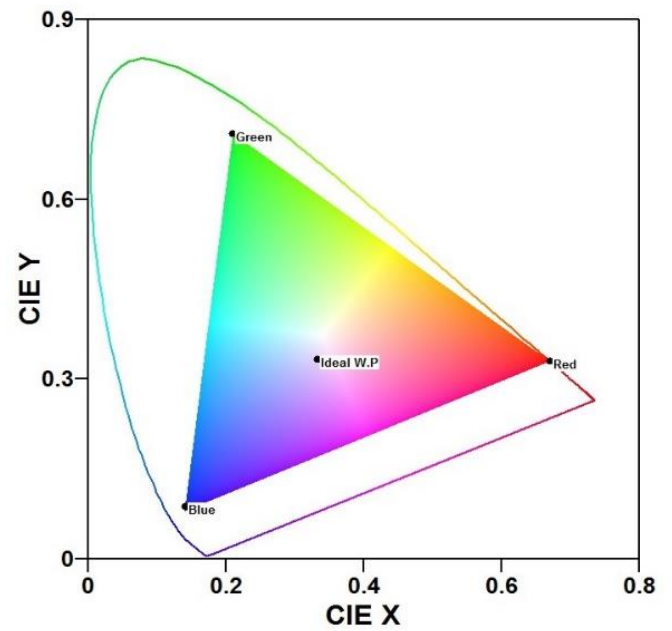

Fig. 3. CIE 1931 chromaticity diagram of the visible gamut [29]

The light source must have the required color point. CIE 1960 chromaticity space is mostly utilized to notice minor color differences [29]. If an area is lightened by more than one lamp, the color variation among all lamps should be close to the minimum-perceptible-color-difference (MPCD) [31].

$$
\Delta u v=\sqrt{\left(u-u_{o}\right)^{2}+\left(v-v_{o}\right)^{2}}
$$

where $(u, v)$ are coordinates of light source and $\left(u_{o}, v_{o}\right)$ are required coordinates of light source.

The color flexibility is the advantage of this technique over phosphor coating technique. It means that, by changing the color point $(u, v)$, the shade of white color can be changed and multi colors are achieved. The facility of varying the color point of lamp impart new attributes in illumination that can possibly create new applications and henceforth new market openings. However, the realization of RGB based white-LEDs encounters some exacting problems.

The white light created by mixing lights emitted from different LEDs has major issue that variation in one color will produce significant change in color point $(u, v)$. Multiple LEDs must possess same color point which is a challenging task as with time and temperature variation may occur in color point. As discussed earlier, LED is a semiconductor device and its energy band gap is affected by temperature which results in change in color output of LED. A proper control system is required to regulate color outputs which add expense. Temperature, spectra responses mismatch and inverted sensor matrix affects the precision of color output. These drawbacks can be avoided by flux feedback (FFB) and temperature feedforward (TFF) methods but these methods are dependent on complex flux measuring techniques [32]. The luminous efficacy of the white light decreases with increasing temperature. The generation of white light from this method has usually low CRI score [33].

\section{PHOSPHOR COATING BASED WHITE-LEDS}

The well-known strategy to produce white-LED is the phosphor coating use, when phosphor layer is fabricated onto blue or ultraviolet chip [34]. The cerium doped yttrium aluminum garnet (YAG: Ce) phosphor is being commonly coated on blue chip to develop a stable white light [35]. The light color properties such as angular color uniformity (ACU), CRI, LEE, correlated color temperature (CCT) are dependent on phosphor characteristics [36]. The phosphor coating based white-LEDs use phosphor whose CRI score is relatively high (70-90+) [37]. Generally, the ultraviolet LED chip is less stable and efficient than blue chip. The III-Nitride semiconductors are remarkable for illumination applications and development in energy efficient high-quality white-LEDs [38-42]. The combination of III-Nitride elements and appropriate downconversion phosphor can produce white light. Upon blue light emission, it is partly absorbed by phosphor coating and remaining part is blended with yellow light of phosphor to produce white light $[43,44]$. This concept is shown in Fig. 4.

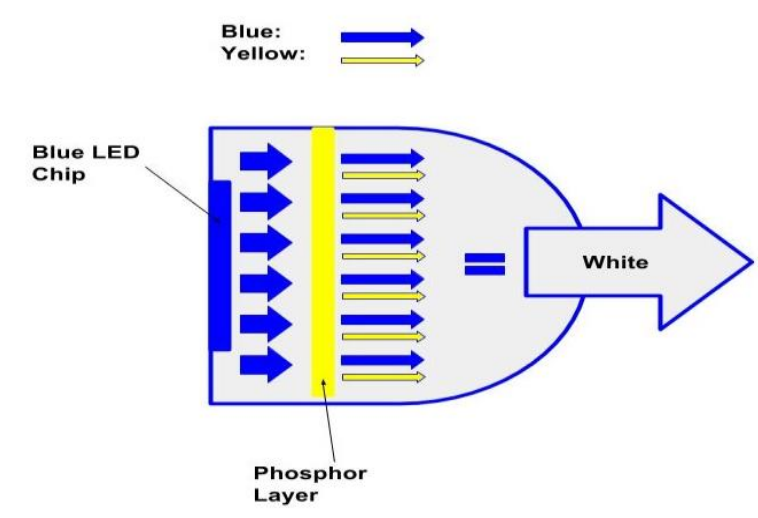

Fig. 4. White light generation with blue LED and yellow phosphor [45]

The precise proportion of blue and yellow light relies on the amount and thickness of phosphor coated on blue LED chip [45]. Several researches have optimized phosphor layer thickness, region of deposition, phosphor concentration, particle size, light extraction efficiency which make phosphor coated LEDs more efficient [45-48]. The AlGaN based deep ultraviolet LEDs face major light extraction problems. The light extraction efficiency is associated with light back-reflected to LED chip which additionally influence the thermal properties of phosphor coated LED by increasing the junction temperature [49,50]. Guo et al. [51] demonstrated a sidewall reflection method which increases light output power (LOP) of $278 \mathrm{~nm}$ 
LEDs by $30 \%$. The geometry of phosphor layer greatly affects optical properties of white LEDs [52]. In general, three configurations are renowned for yellow phosphor coating which are: 1) dispersed or conventional 2) conformal 3) remote. These different configurations provide different optical properties [53].

\section{A. Dispersed Configuration}

In dispersed phosphor configuration, phosphor powder is mixed with slurry and suspended in silicon solution which than deposited on the surface of LED chip. This method has main drawback of non-uniform distribution of phosphor, as shown in Fig. 5.

(a)

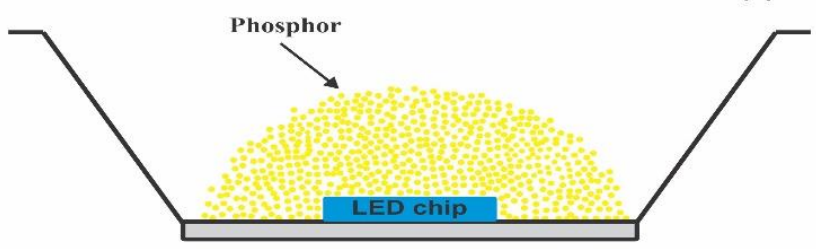

(b)

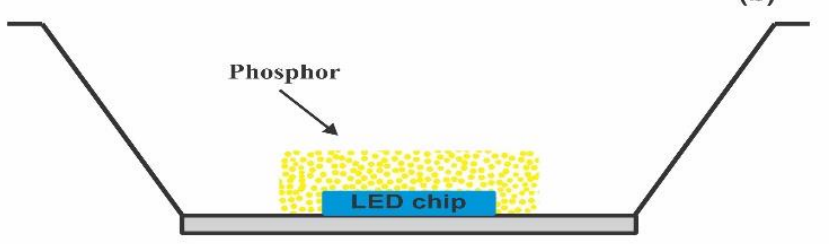

(c)

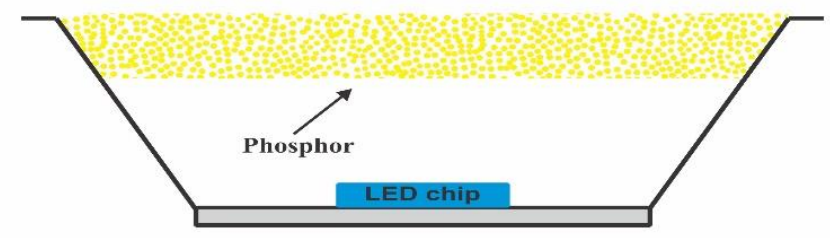

Fig. 5. Different configuration for phosphor coating.

a) Dispersed or conventional coating. b) Conformal coating. c) Remote coating [53]

The dispensing method is used due to low cost phosphor layer, but, as phosphor coating geometry is of spherical shape, it forms a yellow ring with discomfort for eyes. The conventional dispensing method also leads to poor angular color uniformity (ACU) [54]. The settling of phosphor requires for flat surface and, without the provision, it causes a disharmony of blue and yellow lights [55]. The total energy trend of a liquid droplet is always towards minimization and, the shape of liquid droplet, at equilibrium, on a substrate varies for different boundaries [56,57]. Meanwhile, the uniform phosphor coating can be reached in dispersed configuration by adjusting slanting angles of reflector cup, as shown in Fig. 6.

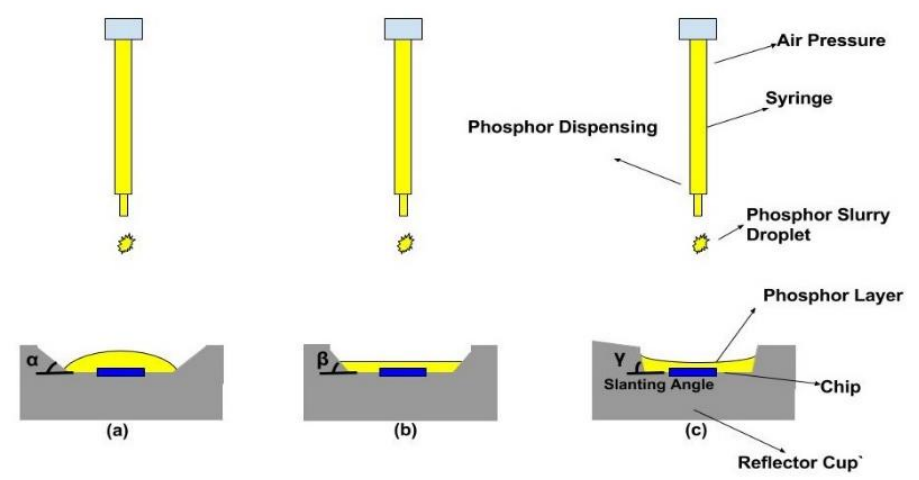

Fig. 6. Different phosphor geometries in reflector cups a) Convex phosphor shape. b) Flat phosphor shape. c) Concave phosphor shape [56]

To overcome the drawbacks of dispersed configuration, the conformal and remote configurations are mostly preferred which are briefly discussed as follows.

\section{B. Conformal Configuration}

Conformal configuration is a well-known phosphor deposition method to control thickness, shape and particle size of phosphor [58-60]. In this way, phosphor is deposited uniformly on outline of blue LED chip, as appear in Fig. 5(b). The conformal phosphor coating of thin phosphor layer can benefit in phosphor layer temperature reduction that increases color stability [61].

$\mathrm{ACU}$ is classified as an important parameter to judge light standards which are generally required high in lighting applications. Inappropriate ACU distresses the eyes, limiting the uses of white LEDs [62]. The phosphor geometry in white LEDs influences the ACU level. The conformal coating provides uniform phosphor layer thickness needed to obtain high ACU [63]. It not only provides better luminous characteristics but also enhances angular correlated color temperature [64]. The conformal coating can achieve good optical performance, but this method creates $50-60 \%$ backscattering light from phosphor layer that decreases the luminous efficacy [65]. Different approaches have been made for conformal deposition which include slurry, self-exposure, electrophoretic deposition, pulse spray, spin coating, wafer level coating and ionic wind pattern [66,67]. The self-exposure, electrophoretic and slurry methods may yield an even phosphor layer, however the chemical procedures may produce chromium ion pollution [68]. Li et al. [64] discussed pulse sprayed conformal phosphor coating wherein light quality of LED has been improved both in multilayer and a mixture of nitride and yellow phosphor. The angular CCT distribution is improved with maximum CCT variation of $257-225 \mathrm{~K}$ for multilayer Y-N LED and mixed N/Y phosphor LED, respectively, which are much lower than that for conventional deposition method. Huang et al. [60] also reduced the color deviation of white LED by pulse spray method. The electrophoretic phosphor deposition (EPD) is another famous method when charged particles in suspension are moved under applied electric field. These charged particles are deposited on oppositely charged electrode. As compared to traditional 
coating, EPD provides better phosphor thickness control along with simple way to reach the conformal configuration with improved color uniformity of LED [69].

An enhanced EPD strategy of wafer level white LED packaging has been proposed in [70]. The results show luminous efficiency of $3.1 \mathrm{~lm} / \mathrm{W}$ and CCT deviation $256 \mathrm{~K}$ which is an exceptional uniformity in CCT and luminous efficiency. Choi et al. [71] performed an experiment to develop a simpler method of conformal phosphor deposition named "quasi-conformal phosphor dispensing". This method saves $50 \%$ phosphor, as compared to conventional phosphor deposition methods. Wu et al. [67] discussed the conformal phosphor coating on ionic wind principle based on their experiments. There results show large optical performance enhancement of white LED and reduced angular CCT deviation from $1630 \mathrm{~K}$ to $366 \mathrm{~K}$.

\section{Remote Configuration}

The remote phosphor method is characterized by a physical separation between LED chip and phosphor layer, as displayed in Fig. 5(c). In conventional and conformal methods, phosphor has direct contact with LED chip that results in high thermal effect on LED chip. The thermal problems may result in lower output light power under high current operation. The phosphor response profoundly relies upon the temperature of LED chip, and, while temperature increases, its emission efficiency decreases. This issue can be solved by remote configuration where a separation exists between the chip and phosphor layer [72,73]. But, despite of the distance, an increase in temperature in phosphor layer affects the life of remote phosphor LED [74]. The thermal isolated encapsulant layer can successfully diminish heat transfer from LED chip to phosphor layer, thus resulting improved luminous efficiency and reduced color variation [75]. Conformal coating has major issue of backscattering light from phosphor layer, which is solved in remote configuration. The remote phosphor configuration reduces the phosphor emission over the LED chip to enhance the luminous efficiency. For maximum light output, the phosphor layer must have appropriate distance from LED chip and backscattered light should be extracted before it is absorbed. The separation between the LED chip and phosphor layer should be long enough so that only small amount of reflected light returns to the chip [76]. A scattered photon extraction (SPE) method has been proposed for remote configuration which shows $60 \%$ improvement in light output by efficient extraction of backscattered light, as compared to white LEDs having phosphor positioned closely to chip [77]. In 2005, another scattered photon extraction (SPE) configuration was introduced where optics were used between remote phosphor layer and LED chip and this shows $60 \%$ improvement in light output [78]. Despite the separation between phosphor layer and LED chip, there are chances that light rays emitted from phosphor layer after being reflected from reflector cup are assimilated by LED chip, as shown in Fig. 7 [79].

To solve this issue, Kim et al. [80] designed a method with diffused reflector cup and remote phosphor configuration. The results show that, as compared to conventional method, their remote method with diffused reflector cup can increase light efficiency by $75 \%$. Lin et al. [81] presented another method by use of inverted cone lens encapsulant and nearby ring remote phosphor layer. The proposed geometry reduced the chances of backward light to be absorbed by LED chip. The results show that light extraction efficiency increased by $93 \%$.

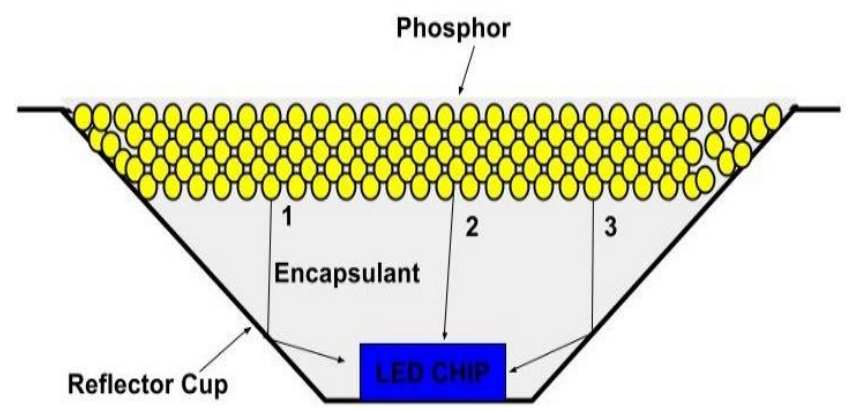

Fig. 7. Light rays reflected from reflector cup and absorbed by LED chip [79].

In remote phosphor configuration, the phosphor nonuniformity may happen because of concave surface encapsulant. The angular dependent optical path causes extra yellow rays which creates a yellow ring outside the LED boundary [82]. A method to achieve high uniformity of angular CCT in white LEDs using $\mathrm{ZrO}_{2}$ nanoparticles is reported on and this improve deviation in CCT by $58 \%$ in comparison to traditional remote phosphor method. The $\mathrm{ZrO}_{2}$ nanoparticles can also solve yellow ring issue in white LEDs and could develop high quality lighting source [83].

\section{THREE BAND White LED TECHNOLOGY}

The traditional strategy to deliver white light with blue LED and yellow phosphor (YAG: Ce) does not produce good CRI [84]. Three band white LED is an interesting technique to produce white color LED with high CRI $[85,86]$. This technique incorporates blue LED coated with red and green phosphor. By the emission of blue light from blue LED, green and red phosphors emit green and red light, respectively. The blue light will only partly be absorbed by phosphors and remaining unabsorbed light combines with red and green light components that results in white light [87]. This technique has an apparent advantage of high CRI and color temperature, as compared to blue LED with yellow phosphor method. The recent experimental results show that three band white LED is extra optically better than YAG: Ce coated white LED [85]. The wide color gamut backlight unit (BLU) using three band white LED has been proposed in [88]. The results show that three-band white LED backlight unit (BLU) color gamut increased by $16 \%$, as compared to conventional white LED BLU. Thus, by three band white LED high color gamut BLU with low cost can be achieved. To obtain more efficient LED, designed methods proposed by different researchers are summarized in Table II. 
TABLE II: METHODS TO IMPROVE EFFICIENCY OF WHITE LED

\begin{tabular}{|c|c|c|}
\hline Refs. & roposed Methodology & Consolidated results \\
\hline $\begin{array}{l}\text { Joshi et al. } \\
{[89]}\end{array}$ & $\begin{array}{l}\text { CdAG: Ce prepared by combustion synthesis coated on } \\
\text { blue LED of } 470 \mathrm{~nm} \text { chip. }\end{array}$ & Improved CRI up to 87. \\
\hline $\begin{array}{l}\text { K. Lee, S. } \\
\text { Lee [90] }\end{array}$ & $\begin{array}{l}\text { Screen-printing approach based, new uniform yellow } \\
\text { phosphor coating method is developed in which silicon } \\
\text { mold plate is fabricated which serves as printing mask. }\end{array}$ & Regulate chromaticity of blue LED. \\
\hline $\begin{array}{l}\text { Chung et } \\
\text { al. [91] }\end{array}$ & $\begin{array}{l}\text { CdSe/ZnSe nanoparticles phosphor is coated on } 460 \mathrm{~nm} \text {, } \\
430 \mathrm{~nm} \text { and } 400 \mathrm{~nm} \text { InGaN chips to fabricate white } \\
\text { LED. }\end{array}$ & $\begin{array}{l}\text { The luminous efficiency of shorter wavelength LED is } \\
\text { enhanced i.e. } 400 \mathrm{~nm}, 430 \mathrm{~nm} \text { and } 460 \mathrm{~nm} \text { LED chip at } 20 \\
\mathrm{~mA} \text { is } 6.57,3.96,2.15 \mathrm{~lm} / \mathrm{W} \text { respectively. }\end{array}$ \\
\hline $\begin{array}{l}\text { Yu et al. } \\
{[92]}\end{array}$ & $\begin{array}{l}\text { White LEDs with microstructure array on top surface of } \\
\text { phosphor silicon layer. }\end{array}$ & $\begin{array}{l}\text { The light extraction efficiency (LEE) is enhanced as } \\
\text { compared to flat phosphor silicone layer i.e. LEE } \\
\text { enhanced by } 12 \% \text { (simulation) and } 10.1 \% \text { (experimental) }\end{array}$ \\
\hline $\begin{array}{l}\text { Akins et } \\
\text { al. [93, } \\
\text { 94] }\end{array}$ & $\begin{array}{l}\text { ZnSe: } \mathrm{Mn} / \mathrm{ZnS} \text { doped core nanocrystal (NCs) and with } \\
\text { quantum dot (QDs) are synthesized separately. }\end{array}$ & $\begin{array}{l}\text { Very high quantum efficiency (QE) } 91.0 \% \text { is achieved in } \\
\text { both cases. }\end{array}$ \\
\hline $\begin{array}{l}\text { Hu et al. } \\
{[95,96]}\end{array}$ & $\begin{array}{l}\text { Bi-layer phosphor model is developed with upper } \\
\text { phosphor layer having concentration of } 0.4 \mathrm{~g} / \mathrm{cm}^{3} \text { and } \\
\text { lower phosphor layer with } 0.05 \mathrm{~g} / \mathrm{cm}^{3} \text { concentration. }\end{array}$ & $\begin{array}{l}\text { Lager concentration of upper phosphor layer than lower } \\
\text { phosphor layer, increases light extraction efficiency } \\
\text { (LEE). }\end{array}$ \\
\hline $\begin{array}{l}\text { Zhou et } \\
\text { al. [97] }\end{array}$ & $\begin{array}{l}\text { A coating method having two phosphor layers is put } \\
\text { forward with conventional convex coating. }\end{array}$ & $\begin{array}{l}\text { Superior stability of blue to yellow proportion at different } \\
\text { angles. Reduces the CCT deviation by } 44 \% \text {. }\end{array}$ \\
\hline $\begin{array}{l}\text { Lan et al. } \\
{[98]}\end{array}$ & $\begin{array}{l}\mathrm{ZrO}_{2} \text { Nano-particle and red phosphor are added in } \\
\text { encapsulant. Different packaging structures of LEDs are } \\
\text { formed and investigated. }\end{array}$ & $\begin{array}{l}\mathrm{ZrO}_{2} \text { Nano-particles increase light scattering ability. } \mathrm{ZrO}_{2} \\
\text { Nano-particles doped with YAG phosphor enhance } \\
\text { luminous flux by } 7.7 \% \text { compared to conventional YAG } \\
\text { doping. } \mathrm{ZrO}_{2} \text { Nano-particle doped in encapsulant with } \\
\text { conformal YAG phosphor LED chip enhance luminous } \\
\text { flux by } 19.8 \% \text { compared to above packaging. Doping } \\
\mathrm{ZrO}_{2} \text { particles with YAG and red phosphor improve CRI } \\
\text { up to } 90 \text {. }\end{array}$ \\
\hline $\begin{array}{l}\text { Liu et al. } \\
\text { [99] }\end{array}$ & $\begin{array}{l}\text { A silicon-based substrate possess low thermal resistance } \\
\text { has been proposed and tested for LED packaging. The } \\
\text { substrate is composed of light-reflection cup with silver } \\
\text { layer coating. }\end{array}$ & $\begin{array}{l}\text { Thermal resistance reduced as compared to ceramic and } \\
\text { lead frame substrate by } 1.965 \text { and } 0.589 \mathrm{~K} / \mathrm{W} \text { respectively } \\
\text { and light output efficiency also increase for silicone-based } \\
\text { package. Less costly. }\end{array}$ \\
\hline $\begin{array}{l}\text { Zhang et } \\
\text { al. [100] }\end{array}$ & $\begin{array}{l}\text { Three multicolor phosphor films having CCT } 3000 \mathrm{k}, \\
4000 \mathrm{k}, 5000 \mathrm{k} \text { are prepared by mixing monochromatic } \\
\text { phosphor powders in silicone. }\end{array}$ & $\begin{array}{l}\text { High CRI and high luminous efficiency are achieved. The } \\
\text { experimental results show the decrease in luminous } \\
\text { intensity by heat treatment from } 30^{\circ} \mathrm{C} \text { to } 150^{\circ} \mathrm{C} \text {. }\end{array}$ \\
\hline $\begin{array}{l}\text { Sun et al. } \\
{[101]}\end{array}$ & $\begin{array}{l}\text { A new structure of spatial-coded coating phosphor } \\
\text { having plates of two sub regions (yellow phosphor and } \\
\text { open windows) is proposed. }\end{array}$ & $\begin{array}{l}\text { Enhances the efficiency of white LED. For CCT around } \\
6500 \mathrm{~K} \text { efficiency is } 68 \% \text { (experimental) and } \\
71.8 \% \text { (simulation). }\end{array}$ \\
\hline $\begin{array}{l}\text { Chen et al. } \\
{[102]}\end{array}$ & $\begin{array}{l}\text { White LED packaging comprise of lens encapsulation, } \\
\text { reflectivity of cavity reflectors and phosphor } \\
\text { concentration are investigated with simulation and } \\
\text { corresponding experiments. }\end{array}$ & $\begin{array}{l}\text { LED packaging is accompanied by high reflectivity of } \\
\text { cavity reflectors to enhance efficiency. }\end{array}$ \\
\hline $\begin{array}{l}\text { K. Chen } \\
\text { et al. [103] }\end{array}$ & $\begin{array}{l}\text { Hybrid warm white high voltage light emitting diodes } \\
\text { (HV-LEDs) are examine by utilizing YAG phosphor, } \\
\text { InGaN and AlGaInP HV-LEDs. }\end{array}$ & $\begin{array}{l}\text { Luminous efficiency of warm hybrid HV-LEDs increases } \\
\text { as compared to conventional cool and warm white LEDs. } \\
\text { Significant improvement of CRI, uniform angular CCT is } \\
\text { observed. }\end{array}$ \\
\hline $\begin{array}{l}\text { Lo et al. } \\
{[104]}\end{array}$ & $\begin{array}{l}\text { Innovative remote phosphor deposition method is } \\
\text { proposed including pre-encapsulated silicon lens. }\end{array}$ & $\begin{array}{l}\text { Uniform white light distribution is achieved with low } \\
\text { manufacturing cost. }\end{array}$ \\
\hline $\begin{array}{l}\text { Yu et al. } \\
{[105]}\end{array}$ & $\begin{array}{l}\text { A double remote micro-patterned phosphor film (double } \\
\text { RMPP film) is presented. Micro-patterned (MP) is } \\
\text { manufactured by spin coating and blend with remote } \\
\text { phosphor film on both sides. }\end{array}$ & $\begin{array}{l}\text { Double RMPP film, enhance the angular color uniformity } \\
\text { (ACU). Results show that this configuration exhibit better } \\
\text { CCT stability than conventional remote phosphor and } \\
\text { single RMPP film. }\end{array}$ \\
\hline
\end{tabular}

\section{HIGH POWER White LEDS AND THERMAL IsSUES}

The white-LEDs which operates over 1 watt are known as high power white-LEDs [106]. The applications of high-power white-LEDs increase day by day and it is expected that the highpower LEDs will become leading illumination technology before 2025 [107]. More heat dissipation takes place by 
increasing the power in LED chip. Thus, thermal management in high power white LEDs is the key issue. High temperature may cause the irreversible damage to phosphor layer, lifetime reduction, wavelength shift and reduce efficiency of phosphor emission $[108,109]$. The amount of heat produced by phosphor layer should be considered while designing the high-power white LEDs. In phosphor, about $8 \%$ of electrical power input is transformed into heat, and, thus, thermal execution of highpower white-LED is affected due to phosphor temperature [110]. Chen et al. [111] prepared LSN Ce and MLSN Ce phosphors and showed that they have better thermal stability than YAG: Ce phosphor for high power warm-light white LEDs. A new ceramic phosphor for high power white LED which ensure better thermal stability and high quantum efficiency has been proposed in [112]. LEDs operating at high power with high junction temperature have great issues on reliability and their performance is associated with thermal management ability [113]. The reliability of LED has direct relation with junction temperature. The greater the temperature of junction, the shorter will be the lifespan of LED. During prolonged usage at elevated operating current $(>350 \mathrm{~mA})$, a high temperature $\left(150-200^{\circ} \mathrm{C}\right)$ originates at junction in high power white LEDs $[114,115]$. The high temperature of junction led to yellowing of organic encapsulants which results in reduction of luminous efficacy and disgrace long-term reliability [116]. To overcome these issues, inorganic encapsulants have been used as substitute [117]. The LED failure cases are mostly temperature related. The junction temperature of LEDs is primarily influenced by following three parameters; LEDs ambient temperature, thermal path between the ambient environment and LED junction, and power dissipated by LED [118].

\section{THERMAL MANAGEMENT IN LEDS}

A typical LED lighting system is facing the issues like decrease in thermal resistance from junction to the substrate, and the accessibility of the orientation free, inexpensive thermal solutions. The efficacy of solid-state lighting devices relying on the temperature of the junction as given in Fig. 8 [119].

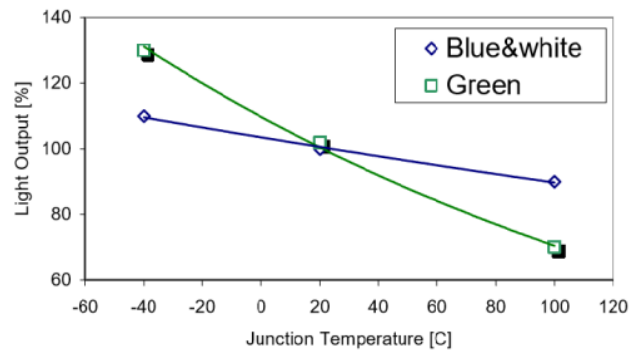

Fig. 8. Light output versus junction temperature [119]

The major heat cause in LED is its generation in active region due to non-radiative recombination process and joule heating at interconnects and series resistance of diode [120]. A typical LED illumination system consist of high brightness packages joined with substrate situated on a heat sink. Heat transfer to the ambient environment takes place through different metallic/non-metallic parts of the package, interface material and heat sinks.

Thermal dissipation path of LED is characterized by thermal resistance which basically shows the ability of system to dissipate heat and is defined between two points as the ratio of temperature difference to the power dissipated along the device. Thermal resistance is usually denoted by $R_{t h}$ with units of K/W or ${ }^{\circ} \mathrm{C} / \mathrm{W}$ and can be obtained by equation $3[121,122]$.

$$
R_{t h}=\Delta T / P_{d}
$$

where $\Delta T$ represent temperature difference between the two ends while $P_{d}$ shows total power dissipated along device. High power LED is commonly placed on metal-core printed circuit board coupled with heat sinks as shown in Fig 9.

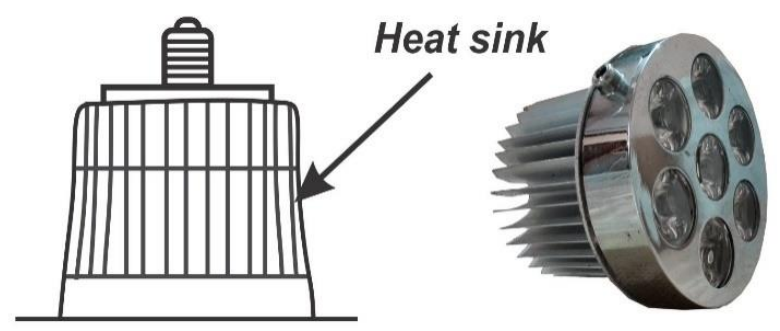

Fig. 9. Heat sink

LED thermal resistance model including heat sink as shown in Fig. 10. Heat from LED junction to heat sink is transferred by conduction while heat from the heat sink spread to ambient surrounding by convection.

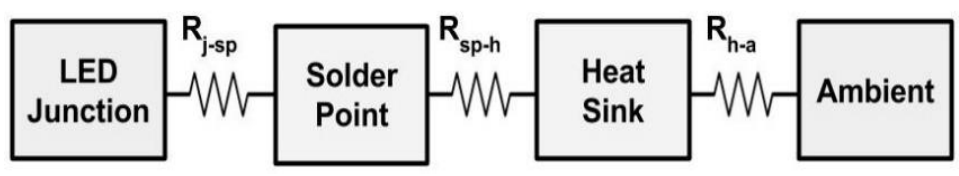

Fig. 10. Thermal Model

The junction temperature $T_{j}$ is defined by equation 4 $[123,124]$.

$$
T_{j}=T_{a}+\left(P_{d} \cdot R_{j-a}\right)
$$

$T_{a}$ is the ambient temperature, $R_{j-a}$ is the thermal resistance from junction to ambient which can be found by following equations.

$$
\begin{aligned}
& R_{j-a}=R_{j-h}+R_{h-a} \\
& R_{j-h}=R_{j-s p}+R_{s p-h} \\
& R_{h-a}=T_{h}-T_{a} / P_{d}
\end{aligned}
$$

where $R_{j-h}$ is the thermal resistance between junction and the heat sink, $R_{h-a}$ is the thermal resistance between heat sink and 
the ambient, $R_{j-s p}$ is the thermal resistance between junction and the soldering point, $R_{s p-h}$ is the thermal resistance between the soldering point and heat sink, $T_{h}$ is the heat sink temperature. Multi-chip LED array die-spacing is important factor to determine the junction temperature [125]. Zhong, Zhang [126] proposed silicon-based heat sink packaging scheme in high power LED to reduce junction temperature.

Developments in LEDs are transforming the lighting industry by creating energy-efficient, durable and environmentally friendly designs of luminaries. However, addressing number of challenges are still required. Most important challenge is thermal management for significant heat created by LEDs. Three approaches of heat transfer are radiation, convection and conduction. However, conduction is the main approach of heat transfer in LEDs. The extensively used LEDs are limited to low power levels due to significant heat transfer through conduction. Contrary, high power LEDs have heat sink fixed in the base of LED case. When attached to specific types of printed circuit boards (PCBs) and other equipment for thermal management, the heat sink in LEDs provides the capacity of more watts in contrast to the widely used LEDs. Power consumption of 4 square inches of heat sink per watt is adopted as a practical and approximately used approach. This approach is effective when the LED is mounted on a PCB which is further mounted on aluminum or copper fixture behaving as a heat sink. Addition of heat sink can be a possibility, but problems like air flow and heat sink can occur if the heat sink is completely enclosed.

The recognized heat sinks are flat plates, die-cast finned heat sinks, and extruded finned heat sinks. However, for the selection of heat sinks surface area, aerodynamics, thermal transfer within the heat sink, flatness of the contact area and mounting methods shall be of great consideration [127]. Phosphor-based Light Emitting Diode (LED) is an increasingly attractive high-power high-brightness white light source. The LED chips in phosphor-based white LEDs, are layered with a phosphor-filled silicone. In the phosphor layer, blue light experiences Strokes shift, in which transformation from shorter wavelength (blue) to longer wavelength (yellow) takes place. The combination of blue and yellow light gives white light. Color rending index (CRI) and efficacy can be enhanced using different colors of phosphors. In the phosphor layer, Stokes shift generates heat and absorbs light, resulting the increase in junction temperature chip. It also increases the temperature of phosphor itself if not dissipated efficiently [128,129]. The excessive temperature generated at the phosphor layer reduces the phosphor emission because of thermal quenching effect [130]. Moreover, damages to the critical components in the emitters and lamps, for example, lifetime reduction [131], wavelength shift [132], silicone yellowing [133] and silicone carbonization [134] can be caused due to high temperature. Phosphors convert $8 \%$ of electrical power into heat Yan et al. [129]. In [135], it has proved that if the chip power efficiency is $30 \%$, around $7 \%$ to $13 \%$ of electrical power provided to the LED chip is converted into heat by the phosphors. This is in consistent with the optical analysis performed by Yan et al. [129].

Reliability of high-power LEDs must consider while developing it. Stress temperature plays a major role in reliability assessment. Optimized stress temperature can assist to analyze the reliability of LED more effectively. It is found that flip and vertical chips enhance heat dissipation of LED more efficiently [136]. They also increase the lifetime of LED. This [137] investigate the thermal effect of phosphor based conformal and remote structures in LEDs. The junction and phosphor temperatures are measured using infrared (IR) thermometer. It is found that conformal structure LED has less phosphor temperature as compared to remote structure which show high heat conduction properties of conformal structure. In addition, lifetime of conformal structure is also better. Packaging of LED has vital contribution in thermal management of LED. Packaging consists of different levels, each of distinct materials. To obtain superior results in thermal management of packaging, each level of packaging along with its interface with other parts should be consider as high potential point. Nano materials and nano fabrication are commonly used to attain high efficiency of LED in smallest possible size [120]. Table III gives a review on different researches aimed to manage thermal issues of high-power LEDs.

TABLE III: THERMAL MANAGEMENT TECHNIQUES FOR HIGH-POWER LED

\begin{tabular}{|l|l|l|}
\hline Refs. & \multicolumn{1}{|c|}{ Methodology } & \multicolumn{1}{c|}{ Findings } \\
\hline $\begin{array}{l}\text { Chakraborty } \\
\text { et al. [138] }\end{array}$ & $\begin{array}{l}\text { High power LEDs fabrication by mask design } \\
\text { comprise of interdigitated multiplex arrays, also } \\
\text { accompanied by extremely low series resistance. }\end{array}$ & $\begin{array}{l}\text { Heat sinking of high-power LEDs is improved and } \\
\text { provides better thermal management. }\end{array}$ \\
\hline $\begin{array}{l}\text { Wang et al. } \\
{[139]}\end{array}$ & $\begin{array}{l}\text { Pure aluminum heat pipe radiator with high } \\
\text { thermal conductivity is investigated for high } \\
\text { power LEDs. }\end{array}$ & Heat pipe enhanced the thermal dissipation effect of LED. \\
\hline $\begin{array}{l}\text { Peng et al. } \\
{[140]}\end{array}$ & $\begin{array}{l}\text { Yellow YAG: Ce based phosphor-in-glass (PiG) } \\
\text { packaging for high power white LED. }\end{array}$ & Improved thermal reliability \\
\hline $\begin{array}{l}\text { Yang et al. } \\
{[141]}\end{array}$ & $\begin{array}{l}\text { Nano-twinned highly (111) textured copper film is } \\
\text { electrodeposited on back of the sapphire substrate. }\end{array}$ & $\begin{array}{l}\text { Enhancement in thermal management of high-power LED } \\
\text { chip. }\end{array}$ \\
\hline $\begin{array}{l}\text { Yuan et al. } \\
{[142]}\end{array}$ & $\begin{array}{l}\text { High power LED array packaging structure } \\
\text { integrated in microchannel cooler module. }\end{array}$ & $\begin{array}{l}\text { Average die temperature reduces and heat dissipation } \\
\text { ability of LED improved. }\end{array}$ \\
\hline
\end{tabular}




\begin{tabular}{|l|l|l|}
\hline $\begin{array}{l}\text { Ding et al. } \\
{[143]}\end{array}$ & $\begin{array}{l}\text { A } 3058 \mathrm{~lm} \text { high power single chip GaN-based } \\
\text { white LED is fabricated and mounted on Cu heat } \\
\text { dissipater. }\end{array}$ & $\begin{array}{l}\text { Cu heat dissipater is significant in managing the heat } \\
\text { produced by high power LED. }\end{array}$ \\
\hline $\begin{array}{l}\text { Tsai et al. } \\
{[144]}\end{array}$ & $\begin{array}{l}\text { High power white LED contain phosphor layer of } \\
\text { Ce: YAG phosphor doped in glass. }\end{array}$ & $\begin{array}{l}\text { Ce: YAG doped glass phosphor layer in LED exhibit high } \\
\text { thermal stability than Ce: YAG doped silicon LED. }\end{array}$ \\
\hline $\begin{array}{l}\text { Fan J et al. } \\
{[145]}\end{array}$ & $\begin{array}{l}\text { InGaN chip-based LED is attached to copper } \\
\text { metal interconnect layer by silver adhesives }\end{array}$ & $\begin{array}{l}\text { Higher thermal conductivity greater than } 20 \mathrm{~W} / \mathrm{mK} \text { is } \\
\text { achieved which is higher than } 0.35 \mathrm{~W} / \mathrm{mK} \text { of conventional } \\
\text { glass fiber epoxy material. }\end{array}$ \\
\hline $\begin{array}{l}\text { Chen Z et al. } \\
{[146]}\end{array}$ & $\begin{array}{l}\text { Grephene oxid solution is coated on phosphor-in- } \\
\text { glass (PiG) by oxidation reduction method in } \\
\text { remote structured LED. }\end{array}$ & $\begin{array}{l}\text { Thermal conductivity increased. Provide superior stability } \\
\text { for high power LEDs. }\end{array}$ \\
\hline
\end{tabular}

\section{VISIBLE LIGHT EMISSION THROUGH NANOMATERIALS}

In recent years, two-dimensional nanomaterials like graphene and molybdenum disulfide $\left(\mathrm{MoS}_{2}\right)$ are investigated for emission of visible light. These analyses include formation of vertical van der Waals heterostructures by stacking distinct two-dimensional semiconductors on top of each other, functioning as LEDs [147]. Nanomaterials emit thermal light at high electron temperature which is achieved by reducing heat dissipation in vertical direction through substrate. Graphene is favorable for optoelectronics applications such as non-linear photonic devices. Graphene on silicon dioxide $\left(\mathrm{SiO}_{2}\right)$ substrates are demonstrated useful as emitters in mid-infrared ranges but bright and broadband light emission in visible range is difficult. This is because the recombination of electron and hole is graphene is inefficient. Superior thermal stability, low heat capacity and high strength of graphene make him suitable for thermal light emission. In past, degradation of dielectric at high temperature limit graphene to infrared range. However, in presence of rapid cooling, temperature of $2800 \mathrm{~K}$ is achieved for thermal light emission in visible range [148]. The interaction of emitted thermal light and reflected light from substrate surface give rise to interference effect which can be utilized to change the wavelength of emitted light [149]. Graphene is robust to support high temperatures and high current densities along with rapid decrease in thermal conductivity. These properties make graphene suitable to work as nanoscale light emitter. Withers F. et al. [147] demonstrate graphene based efficient LED. For this purpose, they carefully stack graphene as a transparent conductive layer, hexagonal boron nitride and semiconducting monolayers.

Transition metal dichalcogenides (TMD) semiconductors having high excitonic photoluminescence and electroluminescence are under research to explore their light emission capabilities. One of its compound molybdenum disulfide $\left(\mathrm{MoS}_{2}\right)$ reveal some special properties such as low thermal conductivity which is useful for emission of visible light. Vertical heat dissipation of this material can be highly reduced by suspending the material in vacuum. Dobusch L et al. [150] showed that monolayer $\mathrm{MoS}_{2}$ can achieve high temperature (around $1600 \mathrm{~K}$ ) in low oxygen partial pressure in vacuum chamber to emit visible light as a result of joule heating.

\section{DISCUSSION AND CONCLUSION}

White-LEDs are fourth generation source of solid-state lighting. Due to growing demand of white-LEDs in market, manufacturers are in search of superior methods to develop them. RGB and phosphor are two main coating approaches to develop white-LEDs. The RGB based white LEDs are advantageous due to flexibility of having multicolor. However, this is not adopted by manufacturers because it requires complex electrical design for output color management. The second method of phosphor coating is more mature and comparatively cheap technology. Its production is easy and good CRI (70-90+) can be achieved. Among phosphor coating configurations, the remote configuration is superior as it resolves the problem of backscattering light by employing SPE method. However, in conformal configuration, luminous efficiency is less because 50-60\% of light is backscattered from phosphor layer even if it is uniformly deposited to obtain high ACU. The dispersed configuration has least luminous efficiency because the non-uniform phosphor distribution results in poor ACU. The life of high-power LEDs is greatly affected by high temperature. Hence, they are coupled with heat sinks which greatly reduces its temperature. Table IV presents the pros, cons along with scope of different white-LED technologies. As LEDs are built with precisely deposited layers of semiconductor materials, tiny changes in thickness of phosphor layer will lead to color changes in LEDs. Furthermore, they are more efficient than incandescent bulbs as they convert half of their electricity to light. Many challenges are still needed to be addressing to attain desirable rate and efficiency. For example, the process of down-conversion offers room for improvement. Additionally, areas such as current efficiency droop, color shift, system reliability, light distribution, dimming, thermal management and power supply performance needs consideration. Improvement in luminaire cost, performance and design flexibility can be done by minimizing high temperature efficiency losses and driving situations for current operation. 
TABLE IV

Assessment of Different White-LED Technologies

\begin{tabular}{|l|l|l|l|}
\hline \multicolumn{1}{|c|}{ White-LED } & \multicolumn{1}{|c|}{ Advantages } & \multicolumn{1}{c|}{ Disadvantages } & \multicolumn{1}{c|}{ Scope } \\
\hline RGB based & $\begin{array}{l}\text { Flexible to achieve desire shade of } \\
\text { white color. }\end{array}$ & $\begin{array}{l}\text { Unstable white light after a time frame } \\
\text { and have low CRI. }\end{array}$ & Limited due to its high cost. \\
\hline Phosphor based & $\begin{array}{l}\text { Stable white light, high luminous } \\
\text { flux and relatively good CRI. }\end{array}$ & $\begin{array}{l}\text { Lack red emission for very high CRI } \\
\text { and have narrow color gamut. }\end{array}$ & $\begin{array}{l}\text { Wide availability due to simple and } \\
\text { inexpensive manufacturing. }\end{array}$ \\
\hline Three band & $\begin{array}{l}\text { Stable, high CRI (>90) and wide } \\
\text { color gamut. }\end{array}$ & $\begin{array}{l}\text { Phosphor starts to saturate at higher } \\
\text { current, causes gradual decrease in } \\
\text { CRI. }\end{array}$ & $\begin{array}{l}\text { High demand where high CRI is } \\
\text { required such as museum gallery } \\
\text { and in hospitals. }\end{array}$ \\
\hline High power & High luminance. & $\begin{array}{l}\text { Overheating due to high driven } \\
\text { current }\end{array}$ & $\begin{array}{l}\text { Leading lighting technology by } \\
2025 .\end{array}$ \\
\hline
\end{tabular}

\section{REFERENCES}

[1] F.G. Montoya, A. Peña-García, A. Juaidi, F. ManzanoAgugliaro, "Indoor lighting techniques: An overview of evolution and new trends for energy saving" Energy Build, vol. 140, pp. 50-60. April 2017.

[2] D. MacIsaac, G. Kanner, G. Anderson, "Basic physics of the incandescent lamp (lightbulb)," Phys. Teach, vol. 37, pp. 520-525, 1999.

[3] M. Schratz, C. Gupta, T.J. Struhs, K. Gray, “A New Way to See the Light: Improving Light Quality with Cost-Effective LED Technology," IEEE Ind. Appl. Mag., vol. 22, pp. 5562, 2016.

[4] A. De Almeida, B. Santos, B. Paolo, M. Quicheron, "Solid state lighting review - Potential and challenges in Europe," Renew. Sustain. Energy Rev., vol. 34, pp. 30-48, 2014.

[5] S. Liu, X. Luo, LED Packaging for Lighting Applications: Design, Manufacturing and Testing, John Wiley \& Sons, New York, 2011.

[6] U.S. Department of Energy, "Solid-State Lighting Research and Development : Multi-Year Program Plan FY 09- 14," Light. Res. Dev. Build. Technol. Progr., 2008.

[7] Energy Information Administration (EIA)- Electricity Explianed : Use of Elecricity, https://www.eia.gov/energyexplained/electricity/use-ofelectricity.php Accessed: 10/14/2019.

[8] M.R. Krames, O.B. Shchekin, R. Mueller-Mach, G.O. Mueller, L. Zhou, G. Harbers, M.G. Craford, "Status and future of high-power light-emitting diodes for solid-state lighting," J. Disp. Technol., vol. 3, pp. 160-175, 2007.

[9] K.H. Lee, S.W. Ricky Lee, "Screen-printing of yellow phosphor powder on blue light emitting diode (LED) arrays for white light illumination." Proc. InterPACK'07. 2007.

[10] S. Nakamura, "Background Story of the Invention of Efficient InGaN Blue-Light-Emitting Diodes (Nobel Lecture)," Angew. Chemie - Int. Ed. vol. 54, pp. 77707788, 2015.

[11] T.Q. Khanh, P. Bodrogi, Q.T. Vinh, H. Winkler, LED Ligthing, Technology and Perception, Wiley-VCH, 2014.

[12] F.K. Yam, Z. Hassan, "Innovative advances in LED technology", Microelectronics J., vol. 36, pp. 129-137, 2005.
[13] F. Bisegna, F. Gugliermetti, M. Barbalace, L. Monti, "Stato dell'arte dei LED (Light Emitting Diodes)" Dipartimento di Fisica tecnica, Università di Roma 'La Sapienza, 2010.

[14] X.A. Cao, S.D. Arthur, "High-power and reliable operation of vertical light-emitting diodes on bulk GaN," Appl. Phys. Lett., vol. 85, pp. 3971-3973, 2004.

[15] Y.C. Yang, J.-K. Sheu, M.-L. Lee, S.-J. Tu, F.-W. Huang, W.-C. Lai, S.J. Hon, T.K. Ko, "Vertical InGaN lightemitting diodes with a sapphire-face-up structure" Opt. Express. vol. 20, pp. 119-24, 2012.

[16] H.W. Huang, H.C. Kuo, C.F. Lai, C.E. Lee, C.W. Chiu, T.C. Lu, S.C. Wang, C.H. Lin, K.M. Leung, "Highperformance GaN-based vertical-injection light-emitting diodes with $\mathrm{TiO} 2-\mathrm{SiO} 2$ omnidirectional reflector and nGaN roughness," IEEE Photonics Technol. Lett. vol. 19, pp. 565-567, 2007

[17] G.G. Lu, M.M. Hao , C.X. Lai , B. Yao, "Thermal analysis and reliability evaluation on high power Flip chip LED." In 12th China International Forum Solid State Lighting (SSLCHINA), pp. 43-46, 2015.

[18] X. Luo, R. Hu, S. Liu, K. Wang, "Heat and fluid flow in high-power LED packaging and applications" Prog. Energy Combust. Sci. vol. 56, pp. 1-32, 2016.

[19] S.W.R. Lee, X. Guo, D. Niu, J.C.C. Lo, "Quasi-conformal phosphor dispensing on LED for white light illumination" in: Proc. - Electron. Components Technol. Conf., pp. 563 567, 2013.

[20] S. Pimputkar, J.S. Speck, S.P. Denbaars, S. Nakamura, "Prospects for LED lighting" Nat. Photonics. vol. 3, pp. 180-182, 2009.

[21] K. Smet, Jost-Boissard S, Ryckaert WR, Deconinck G, Hanselaer P., "Validation of a colour rendering index based on memory colours" CIE Lighting Quality \& Energy Efficiency, vol. 35, pp. 136-142, 2010.

[22] U. Happek, Basics of Lighting: Efficacy, "Color Rendering, and Color Temperature" The Electrochemical Society interface, vol. 18, pp. 29-30, 2009.

[23] Z. Lei, G. Xia, L. Ting, G. Xiaoling, L. Qiao Ming, S. Guangdi, "Color rendering and luminous efficacy of trichromatic and tetrachromatic LED-based white LEDs" Microelectronics J., vol. 38, pp. 1-6, 2007. 
[24] H.S. Choi, J.S. Park, C.H. Moon, "Improvement of light extraction efficiency of LED packages using an enhanced encapsulant design” J. Opt. Soc. Korea., vol. 18, pp. 370376, 2014.

[25] U.S. Department of Energy. "Color Quality of White LEDs" Report 2008, pp.1-2.

[26] A. Kar, A. Kar, "Advancements in solid state lighting technology for smart and energy efficient illumination system design" Proceeding IEEE Int. Conf. Green Comput. Commun. Electr. Eng. ICGCCEE 2014, 2014.

[27] S. Muthu, J. Gaines, "Red, Green and Blue LED-based White Light Source: Implementation Challenges and Control Design," Industry Applications Conference, 2003. 38th IAS Annual Meeting. IEEE, vol. 1, pp. 515-522, 2003.

[28] S. Muthu, F.J.P. Schuurmans, M.D. Pashley, "Red, green, and blue LEDs for white light illumination" IEEE J. Sel. Top. Quantum Electron. vol. 8, pp. 333-338, 2002.

[29] J. Schanda, Colorimetry: Understanding the CIE System, Wiley, 2007.

[30] K.T. Kamtekar, A.P. Monkman, M.R. Bryce, "Recent advances in white organic light-emitting materials and devices (WOLEDS)" Adv. Mater., vol. 22, pp. 572-582, 2010.

[31] MacAdam, D. L., Color Measurements: Theme and Variations, Springer-Verlag, New York, 1981.

[32] C.W. Tang, B.J. Huang, S.P. Ying, "Illumination and color control in red-green-blue light-emitting diode" IEEE Trans. Power Electron. vol. 29, pp. 4921-4937, 2014.

[33] S. Muthu, F.J. Schuurmans, M.D. Pashley, "Red, green, and blue LED based white light generation: issues and control" Conf. Rec. 2002 IEEE Ind. Appl. Conf. 37th IAS Annu. Meet. (Cat. No.02CH37344). vol.1, pp. 327-333, 2002.

[34] J. Zhang, W. Guo, B. Xie, X. Yu, X. Luo, T. Zhang, Z. Yu, H. Wang, X. Jin, "Blue light hazard optimization for white light-emitting diode sources with high luminous efficacy of radiation and high color rendering index" Opt. Laser Technol. vol. 94, pp. 193-198, 2017.

[35] S.W. Yoon, H.K. Park, J.H. Oh, Y.R. Do, "Full extraction of 2D photonic crystal assisted Y3Al5O12:Ce ceramic plate phosphor for highly efficient white LEDs" IEEE Photonics J. vol. 6, 2014.

[36] R.Yu, S. Jin , S. Cen, P. Liang, "Effect of phosphor geometry on luminous flux of phosphor-converted LED" IEEE Photon. Technol. Lett. vol. 22, pp. 1765-1767, 2010.

[37] U.S. Department of Energy. "LED Measurement Series: Color Rendering Index and LEDs” Report, pp. 1-2, 2008.

[38] H. Hardtdegen, M. Mikulics, "Towards III-nitride nanoLED based single photon emitters: Technology and applications" ASDAM 2016 - Conf. Proceedings, 11th Int. Conf. Adv. Semicond. Devices Microsystems, pp. 27-32, 2017.

[39] Y.K. Ee, J.M. Biser, W. Cao, H.M. Chan, R.P. Vinci, N. Tansu, "Metalorganic vapor phase epitaxy of III-nitride light-emitting diodes on nanopatterned AGOG sapphire substrate by abbreviated growth mode" IEEE J. Sel. Top. Quantum Electron. vol. 15, pp. 1066-1072, 2009.

[40] C. Lee, C. Zhang, D. Becerra, S. Lee, S.H. Oh, R.M. Farrell, J.S. Speck, S. Nakamura, J.E. Bowers, S.P.
DenBaars, "High speed performance of III-nitride laser diode grown on (2021) semipolar plane for visible light communication” 2016 IEEE Photonics Conf. IPC 2016, pp. 809-810, 2017.

[41] C.H. Chao, S.L. Chuang, T.L. Wu, "Theoretical demonstration of enhancement of light extraction of flipchip GaN light-emitting diodes with photonic crystals" Appl. Phys. Lett., vol. 89, 2006.

[42] T. Jung, L.K. Lee, P.C. Ku, "Novel epitaxial nanostructures for the improvement of InGaN LEDs efficiency" IEEE J. Sel. Top. Quantum Electron. vol. 15, pp. 1073-1079, 2009.

[43] X.H. Li, R. Song, Y.K. Ee, P. Kumnorkaew, J.F. Gilchrist, N. Tansu, "Light extraction efficiency and radiation patterns of III-nitride light-emitting diodes with colloidal microlens arrays with various aspect ratios" IEEE Photonics J. vol. 3, pp. 489-499, 2011.

[44] J.J. Wierer, A. David, M.M. Megens, "III-nitride photoniccrystal light-emitting diodes with high extraction efficiency" Nat. Photonics. vol. 3, pp. 163-169, 2009.

[45] Z.Y. Liu, S. Liu, K. Wang, X.B. Luo, "Studies on optical consistency of white LEDs affected by phosphor thickness and concentration using optical simulation" IEEE Trans. Components Packag. Technol. vol. 33, pp. 680-687, 2010.

[46] Z. Liu, S. Liu, K. Wang, X. Luo, “Optical Analysis of Phosphor's Location for High-Power Light-Emitting Diodes" IEEE Trans. Device Mater. Reliab., vol. 9, pp. 65-73, 2009.

[47] C. Sommer, F. Reil, J.R. Krenn, P. Hartmann, P. Pachler, S. Tasch, F.P. Wenzl, "The impact of inhomogeneities in the phosphor distribution on the device performance of phosphor-converted high-power white LED light sources" J. Light. Technol. vol. 28, pp. 3226-3232, 2010.

[48] S.C. Huang, J.K. Wu, W.J. Hsu, H.H. Chang, H.Y. Hung, C.L. Lin, H.Y. Su, N. Bagkar, W.C. Ke, H.T. Kuo, R.S. Liu, "Particle size effect on the packaging performance of YAG:Ce phosphors in white LEDs" Int. J. Appl. Ceram. Technol. vol. 6, pp. 465-469, 2009.

[49] J.J. Wierer, A.A. Allerman, I. Monta??o, M.W. Moseley, "Influence of optical polarization on the improvement of light extraction efficiency from reflective scattering structures in AlGaN ultraviolet light-emitting diodes" Appl. Phys. Lett., vol. 105, 2014.

[50] J.P. You, N.T. Tran, F.G. Shi, "Light extraction enhanced white light-emitting diodes with multi-layered phosphor configuration.," Opt. Express. vol. 18, pp. 5055-5060, 2010.

[51] Y. Guo, Y. Zhang, J. Yan, X. Chen, S. Zhang, J. Wang, et al. "Enhancement of Light Extraction on AlGaN-based Deep-Ultraviolet Light-Emitting Diodes Using a Sidewall Reflection Method" 13th China International Forum On Solid State Lighting, Beijing, China: IEEE, pp. 127-30, 2016.

[52] Won YH, Jang HS, Cho KW, Song YS. "Effect of Phosphor Geometry on the luminous Efficiency of HighPower White Light-Emitting Diodes with Excellent Color Rendering Property" Optical Letters. vol. 34, pp. 1-3, 2009. 
[53] H. Rao, W. Wang, X. Wan, L. Zhou, J. Liao, D. Zhou, Q. Lei, X. Wang, "An improved slurry method of selfadaptive phosphor coating for white pc-LED packaging" J. Disp. Technol. vol. 9, pp. 453-458, 2013.

[54] Z. Liu, S. Liu, K. Wang, X. Luo, “Optical analysis of color distribution in white LEDs with various packaging methods" IEEE Photonics Technol. Lett. vol. 20, pp. 2027-2029, 2008.

[55] X. Huang, "Solid-state lighting: Red phosphor converts white LEDs" Nat. Photonics. vol. 8, pp. 748-749, 2014.

[56] Q. Liao, Y. Shi, Y. Fan, X. Zhu, H. Wang, "Numerical simulations of the equilibrium shape of liquid droplets on gradient surfaces" Appl. Therm. Eng. vol. 29, pp. 372379, 2009.

[57] V.A. Lubarda, K.A. Talke, "Analysis of the equilibrium droplet shape based on an ellipsoidal droplet model" Langmuir., vol. 27, pp. 10705-10713, 2011.

[58] H. Zheng, J. Ma, X. Luo, "Conformal phosphor distribution for white lighting emitting diode packaging by conventional dispensing coating method with structure control" IEEE Trans. Components, Packag. Manuf. Technol. vol. 3, pp. 417-421, 2013.

[59] R. Hu, X. Luo, S. Liu, "Study on the Optical Properties of Conformal Coating Light-Emitting Diode by Monte Carlo Simulation" Photonics Technol. Lett. IEEE. vol. 23, pp. 1673-1675, 2011.

[60] H.T. Huang, C.C. Tsai, Y.P. Huang, "Conformal phosphor coating using pulsed spray to reduce color deviation of white LEDs” Opt. Express. vol. 18, pp. A201-A206, 2010.

[61] X. Luo, X. Fu, F. Chen, H. Zheng, "Phosphor self-heating in phosphor converted light emitting diode packaging," Int. J. Heat Mass Transf. vol. 58, pp. 276-281, 2013.

[62] B. Wu, X. Luo, H. Zheng, S. Liu, "Effect of gold wire bonding process on angular correlated color temperature uniformity of white light-emitting diode," Opt. Express, vol. 19, pp. 24115-24121, 2011.

[63] H. Zheng, X. Luo, R. Hu, B. Cao, X. Fu, Y. Wang, S. Liu, "Conformal phosphor coating using capillary microchannel for controlling color deviation of phosphorconverted white light-emitting diodes," Opt. Express, vol. 20, pp. 5092-5098, 2012.

[64] Z.T. Li, Y. Tang, Z.Y. Liu, Y.E. Tan, B.M. Zhu, "Detailed study on pulse-sprayed conformal phosphor configurations for LEDs," J. Disp. Technol., vol. 9, pp. 433-440, 2013.

[65] Lin H-T, Tien C-H, Hsu C-P, Horng R-H., "White thinfilm flip-chip LEDs with uniform color temperature using laser lift-off and conformal phosphor coating technologies" Opt. Express, vol. 22, 2014.

[66] K. Chen, R. Zhang, S.W.R. Lee, "Integration of phosphor printing and encapsulant dispensing processes for wafer level LED array packaging," Proc. - 2010 11th Int. Conf. Electron. Packag. Technol. High Density Packag. ICEPTHDP, pp. 1386-1392, 2010.

[67] J. Wu, J. Chu, Z. Zhang, X. Lei, C. Xu, H. Zheng, J. Huang, S. Liu, "Study on conformal phosphor coating for phosphor converted white LEDs through ionic wind patterning," 17th Int. Conf. Electron. Packag. Technol. ICEPT, pp. 1051-1054, 2016.
[68] B. Hou, H. Rao, J. Li, "Methods of increasing luminous efficiency of phosphor-converted LED realized by conformal phosphor coating," IEEE/OSA J. Disp. Technol., vol. 5, pp. 57-60, 2009.

[69] M.J. Santillán, F. Membrives, N. Quaranta, A.R. Boccaccini, "Characterization of $\mathrm{TiO} 2$ nanoparticle suspensions for electrophoretic deposition," J. Nanoparticle Res., vol. 10, pp. 787-793, 2008.

[70] X. Wang, H. Rao, W. Zhang, Q. Lei, D. Zhou, Q. Zhang, C. Li, C. Zhou, "An Improved Electrophoretic Deposition Method for Wafer Level White PC-LED Array Packaging," J. Disp. Technol., vol. 12, pp. 1609-1612, 2016.

[71] J.I. Choi, M. Anc, A. Piquette, M.E. Hannah, K.C. Mishira, J. Mckittrick, et al., "White-emitting solid-state lighting by electrophoretic deposition of phosphors," IEEE Photonics Conference 2012. pp. 903-904, 2012.

[72] H. Zheng, X. Fu, R. Hu, S. Liu, X. Luo, “Angular color uniformity improvement for phosphor-converted white light-emitting diodes by optimizing remote coating phosphor geometry," 13th Int. Conf. Electron. Packag. Technol. High Density Packag., pp. 1483-1486, 2012.

[73] J.C.C. Lo, S.W.R. Lee, X. Guo, H. Zhao, "Multilayer dispensing of remote phosphor for LED wafer level packaging with pre-formed silicone lens," 5th Conf. Electron. Syst. Technol., 2014.

[74] I.U. Perera, N. Narendran, "Understanding heat dissipation of a remote phosphor layer in an LED system," Intersoc. Conf. Thermomechanical Phenom. Electron. Syst., pp. 186-192, 2014.

[75] B. Fan, H. Wu, Y. Zhao, Y. Xian, G. Wang, "Study of phosphor thermal-isolated packaging technologies for high-power white light-emitting diodes," IEEE Photonics Technol. Lett., vol. 19, pp. 1121-1123, 2007.

[76] S.C. Allen, A.J. Steckl, "ELiXIR - Solid-state luminaire with enhanced light extraction by internal reflection," IEEE/OSA J. Disp. Technol., vol. 3, pp. 155-159, 2007.

[77] N. Narendran, "Improved Performance White LED," Fifth Int. Conf. Solid State Light., pp. 1-6, 2005.

[78] N. Narendran, Y. Gu, J.P. Freyssinier-Nova, Y. Zhu, "Extracting phosphor-scattered photons to improve white LED efficiency," Phys. Status Solidi Appl. Mater. Sci., vol. 202, 2005.

[79] Y. Zhu, N. Narendran, "Optimizing the Performance of Remote Phosphor LEDs,” J. Light Vis. Environ., vol. 32, pp. 115-119, 2008.

[80] J.K. Kim, H. Luo, E.F. Schubert, J. Cho, C. Sone, Y. Park, "Strongly enhanced phosphor efficiency in GaInN white light-emitting diodes using remote phosphor configuration and diffuse reflector cup," Japanese J. Appl. Physics, Part 2 Lett., vol. 44, 2005.

[81] M. Te Lin, M.Y. Lin, K.Y. Tai, S.C. Tai, C.H. Liu, S.P. Ying, J.C. Chen, C.C. Sun, "Ring Remote Phosphor Structure for Phosphor-Converted White LEDs," IEEE Photonics Technol. Lett., vol. 22, pp. 574-576, 2010.

[82] H.-C. Kuo, C.-W. Hung, H.-C. Chen, K.-J. Chen, C.-H. Wang, C.-W. Sher, C.-C. Yeh, C.-C. Lin, C.-H. Chen, Y.J. Cheng, "Patterned structure of remote phosphor for phosphor-converted white LEDs," Opt. Express., vol. 19, pp. A930-A936, 2011. 
[83] K.-J. Chen, C. Hsin-Chu, L. Chien-Chung, W. Chao-Hsun, T. Hsin-Han, C. Shih-Hsuan, et al., "High Uniformity of Remote Phosphor Structure by $\mathrm{ZrO} 2$ Nano-particles for White LEDs," Asia Communications and Photonics Conference, pp. 1-3, 2012.

[84] R.H. Horng, P. Han, D.S. Wuu, "Phosphor-free white light from InGan blue and green light-emitting diode chips covered with semiconductor-conversion AlGaInP epilayer," IEEE Photonics Technol. Lett., vol. 20, 11391141, 2008.

[85] H. Wu, X. Zhang, C. Guo, J. Xu, M. Wu, Q. Su, "Threeband white light from InGaN-based blue LED chip precoated with green/red phosphors," IEEE Photonics Technol. Lett., vol. 17, pp. 1160-1162, 2005.

[86] Y.-D. Huh, J.-H. Shim, Y. Kim, Y.R. Do, "Optical Properties of Three-Band White Light Emitting Diodes," Journal of The Electrochemical Society, vol. 150, pp. H57H60, 2003.

[87] C.C. Yang, C.M. Lin, Y.J. Chen, Y.T. Wu, S.R. Chuang, R.S. Liu, S.F. Hu, "Highly stable three-band white light from an InGaN-based blue light-emitting diode chip precoated with (oxy)nitride green/red phosphors," Appl. Phys. Lett., vol. 90, 2007.

[88] L. Kim, K. Chung, "Wide color gamut backlight from three-band white LED," J. Opt. Soc. Korea., vol. 11, pp. 67-70, 2007.

[89] C. Joshi, P. Yadav, S. V. Moharil, "Improved white light emitting diode characteristics by coating GdAG:Ce phosphor," Trans. Electr. Electron. Mater., vol. 15, pp. 6972, 2014.

[90] K.H. Lee, S.W.R. Lee, "Process development for yellow phosphor coating on blue light emitting diodes (LEDs) for white light illumination," Proc. Electron. Packag. Technol. Conf. EPTC, pp. 379-384, 2006.

[91] W. Chung, H.J. Yu, S.H. Kim, "White emission from $\mathrm{CdSe} / \mathrm{ZnSe}$ nanoparticles combining with 400,430 and 460nm InGaN LED," 10th IEEE International Conference on Nanotechnology, pp. 962-965, 2010.

[92] S. Yu, R. Hu, M. Chen, S. Liu, "Improvement of light extraction efficiency of white LEDs using microstructure array on phosphor silicone layer," 2012 13th International Conference on Electronic Packaging Technology \& HighDensity Packaging, pp. 674-677, 2012.

[93] B.A. Akins, A.C. Rivera, N.C. Cook, G.A. Smolyakov, M. Osinski, "ZnSe:Mn/ZnS High Temperature Nanophosphors with Very High Quantum Efficiency for White LEDs," Conference on Lasers and Electro-Optics 2012, 2012.

[94] B.A. Akins, S.A. Ivanov, J.B. Plumley, S.M. Stephens, N.C. Cook, G.A. Smolyakov, M. Osinski, "Hightemperature $\mathrm{ZnSe}: \mathrm{Mn} / \mathrm{ZnS}$ nanophosphors with very high quantum efficiency for white LEDs" In Lasers and ElectroOptics Pacific Rim (CLEO-PR), 2013.

[95] R. Hu, B. Cao, Y. Zou, Y. Zhu, S. Liu, X. Luo, "Modeling the light extraction efficiency of bi-layer phosphors in white LEDs," IEEE Photonics Technol. Lett., vol. 25, pp. 11411144, 2013.

[96] R. Hu, Y. Wang, X. Luo, X. Zhang, L. Yang, "Light extraction efficiency enhancement of white LEDs by bilayer phosphor configuration," Proc. - 2013 14th Int. Conf.
Electron. Packag. Technol. ICEPT 2013, pp. 214-216, 2013.

[97] D. Zhou, H. Rao, Q. Lei, X. Wang, X. Wan, “A new coating configuration with two phosphor layers laminated for white PC-LEDs," 10th China International Forum on Solid State Lighting (ChinaSSL), pp. 12-15, 2013.

[98] Y.-C. Lan, C.-L. Lin, W.-S. Wang, Z.-Y. Liu, B.-S. Hsieh, S.-L. Chen, et al., "Improving efficiency and light quality of white LEDs by adding $\mathrm{ZrO} 2$ nano-particle and red phosphor in encapsulant," 2016 5th International Symposium on Next-Generation Electronics (ISNE), pp. 1-2, 2016.

[99] X. Liu, Z. Lv, S. Liu, "Low Thermal-Resistance SiliconBased Substrate for Light-Emitting Diode Packaging," IEEE Trans. Components, Packag. Manuf. Technol., vol. 5, pp. 1387-1392, 2015.

[100] M. Zhang, J. Fan, C. Qian, X. Fan, A. Ji, G. Zhang, "Analysis of photoluminescence mechanisms and thermal quenching effects for multicolor phosphor films used in high color rendering white LEDs," 2016 17th International Conference on Electronic Packaging Technology (ICEPT), pp. 334-340, 2016.

[101] C.C. Sun, Y.Y. Chang, C.Y. Lu, H.Y. Lin, Z.Y. Ting, T.H. Yang, T.Y. Chung, Y.W. Yu, "Spatial-Coded Phosphor Coating for High-Efficiency White LEDs," IEEE Photonics J., vol. 9, 2017.

[102] C.Y. Chen, T.H. Yang, C.H. Hsu, C.C. Sun, "Highefficiency white LED packaging with reduced phosphor concentration," IEEE Photonics Technol. Lett., vol. 25, pp. 694-696, 2013.

[103] K.J. Chen, H.T. Kuo, Y.C. Chiang, H.C. Chen, C.H. Wang, M.H. Shih, C.C. Lin, C.J. Pan, H.C. Kuo, "Efficiency and droop improvement in hybrid warm white LEDs using InGaN and AlGaInP high-voltage LEDs,” IEEE/OSA J. Disp. Technol., vol. 9, pp. 280$284,2013$.

[104] J.C.C. Lo, H. Liu, S.W.R. Lee, X. Guo, H. Zhao, "Remote phosphor deposition on LED arrays with preencapsulated silicone lens," 2013 14th Int. Conf. Therm. Mech. Multi-Physics Simul. Exp. Microelectron. Microsystems, EuroSimE, 2013.

[105] S. Yu, Z. Li, G. Liang, Y. Tang, B. Yu, K. Chen, “Angular color uniformity enhancement of white light-emitting diodes by remote micro-patterned phosphor film," Photonics Research, vol. 4, pp. 140-145, 2016.

[106] B. Sun, X. Jiang, K.C. Yung, J. Fan, M.G. Pecht, “A Review of Prognostic Techniques for High-Power White LEDs," IEEE Trans. Power Electron., vol. 32, pp. 63386362, 2017.

[107] X. Luo, W. Xiong, T. Cheng, S. Liu, "Temperature estimation of high-power light emitting diode street lamp by a multi-chip analytical solution," IET Optoelectron., vol. 3, pp. 225-232, 2009.

[108] J.H. Hwang, Y.D. Kim, J.W. Kim, S.J. Jung, H.K. Kwon, T.H. Oh, "Study on the effect of the relative position of the phosphor layer in the LED package on the high power LED lifetime," Phys. Status Solidi Curr. Top. Solid State Phys., pp. 2157-2161, 2010.

[109] M. Huang, L. Yang, "Heat generation by the phosphor layer of high-power white LED emitters," IEEE Photonics Technol. Lett., vol. 25, pp. 1317-1320, 2013. 
[110] B. Yan, N.T. Tran, J.P. You, F.G. Shi, "Can junction temperature alone characterize thermal performance of white LED emitters?," IEEE Photonics Technol. Lett., vol. 23, pp. 555-557, 2011.

[111] Z. Chen, Q. Zhang, Y. Li, H. Wang, R.J. Xie, "A promising orange-yellow-emitting phosphor for high power warm-light white LEDs: Pure-phase synthesis and photoluminescence properties," J. Alloys Compd., vol. 715, pp. 184-191, 2017.

[112] K. Li, H. Wang, X. Liu, W. Wang, Z. Fu, "Mn2+activated MgAlON transparent ceramic: A new green-emitting transparent ceramic phosphor for high-power white LED," J. Eur. Ceram. Soc., vol. 37, pp. 4229-4233, 2017.

[113] X. Yang, Z. Wang, Y. Ren, B. Sun, "Thermal effects of packaging material and structure on high power white LEDs," 2016 17th International Conference on Electronic Packaging Technology (ICEPT), pp. 13501354, 2016.

[114] X. Luo, X. Fu, F. Chen, H. Zheng, "Phosphor self-heating in phosphor converted light emitting diode packaging," Int. J. Heat Mass Transf., vol. 58, pp. 276-281, 2013.

[115] X. Luo, R. Hu, S. Liu, K. Wang, "Heat and fluid flow in high-power LED packaging and applications," Prog. Energy Combust. Sci., vol. 56, pp. 1-32, 2016.

[116] Lin, H. Lin, J. Xu, F. Huang, H. Chen, B. Wang, Y. Wang, "Highly thermal-stable warm w-LED based on Ce:YAG PiG stacked with a red phosphor layer," J. Alloys Compd., vol. 649, pp. 661-665, 2015.

[117] N. Wei, T. Lu, F. Li, W. Zhang, B. Ma, Z. Lu, J. Qi, "Transparent Ce:Y 3Al $5 \mathrm{O} 12$ ceramic phosphors for white light-emitting diodes," Appl. Phys. Lett., vol. 101, 2012.

[118] F. Ruknudeen, S. Gervasis, V. Viswambharan, S. Asokan, "An On-Board Life Estimation Technique for Lights Using High Power White LEDs," Journal of Display Technology, vol. 12, pp. 938-945, 2016.

[119] Arik, M., Weaver, S., Becker, C., Hsing, M. and Srivastava, A, "Effects of Localized Heat Generations Due to The Color Conversion in Phosphor Particles and Layers of High Brightness Light Emitting Diodes", ASME/IEEE International Electronic Packaging Technical Conference and Exhibition - InterPACK'03, Hawaii, USA, July 6-11, 2003.

[120] Hamidnia M, Luo Y, Wang XD. "Application of micro/nano technology for thermal management of high power LED packaging-A review", Applied Thermal Engineering, vol. 145, pp. 637-651, Dec 2018.

[121] M. Lenz, G. Striedl, U. Fröhler, Thermal Resistance, Theory and Practice, Infineon Technologies AG, Germany, 2000.

[122] T.M. Roffi, I. Idris, K. Uchida, S. Nozaki, N. Sugiyama, H. Morisaki, F.X.N. Soelami, "Improvement of highpower-white-LED lamp performance by liquid injection", Proc. 2011 Int. Conf. Electr. Eng. Informatics, pp. 1-6, July 2011.

[123] F. Ruknudeen, S. Gervasis, V. Viswambharan, S. Asokan, "An on-board life estimation technique for lights using high power white LEDs", J. Display Technol., vol. 12, no. 6, pp. 938-945, 2016.
[124] N. Seshasayee, Understanding Thermal Dissipation and Design of a Heatsink, Texas Instruments, Dallas, pp. 1-4 2011.

[125] Ha, Min Seok. "Thermal analysis of high power LED arrays". PhD. Diss., Georgia Institute of Technology, 2009.

[126] D. Zhong, J. Zhang, "Thermal and optical simulation of high-power LED array based on silicon heatsink", Int. Conf. Electron. Commun. Control. ICECC 2011 - Proc., pp. 4043-4046, 2011.

[127] K. Fumagalli, R. Faranda, L. Farne, “Analysis of possible LED failure mode," 11th Pet. Chem. Ind. Conf. Eur. Electr. Instrum. Appl. PCIC, pp. 1-8, 2014.

[128] M. Arik, S. Weaver, C. Becker, M. Hsing, and A. Srivastave, "Effects of localized heat generations due to the color conversion in phosphor particles and layers of high brightness light emitting diodes," Proc. Int. Electron. Packag. Tech. Conf. Exhibit., Maui, HI, USA, pp. 611619, Jul. 2003.

[129] B. Yan, N. T. Tran, J.-P. You, and F. G. Shi, "Can junction temperature alone characterize thermal performance of white LED emitters?" IEEE Photon. Technol. Lett., vol. 23, no. 9, pp. 555-557, 2011.

[130] T. Tamura, T. Setomoto, and T. Taguchi, "Illumination characteristics of lighting array using 10 candela-class white LEDs under AC $100 \mathrm{~V}$ operation," J. Lumin., vols. 87-89, pp. 1180-1182, May 2000.

[131] J.-H. Hwang, Y.-D. Kim, J.-W. Kim, S.-J. Jung, H.-K. Kwon, and T.-H. Oh, "Study on the effect of the relative position of the phosphor layer in the LED package on the high-power LED lifetime," Phys. Status Solidi C, vol. 7, nos. 7-8, pp. 2157-2161, 2010.

[132] Q. Zhang, F. Jiao, Z. Chen, L. Xu, A. Wang, and S. Liu, "Effect of temperature and moisture on the luminescence properties of silicone filled with YAG phosphor," J. Semicond., vol. 32, no. 1, p. 012002, 2011.

[133] N. Narendran, Y. Gu, J. P. Freyssinier, H. Yu, and L. Deng, "Solid-state lighting: Failure analysis of white LEDs," J. Cryst. Growth, vol. 268, nos. 3-4, pp. 449-456, 2004.

[134] X. Luo, X. Fu, F. Chen, and H. Zheng, "Phosphor selfheating in phosphor converted light emitting diode packaging," Int. J. Heat Mass Transf., vol. 58, pp. 276281, Mar. 2013.

[135] Min Huang and Liyu Yang, "Heat Generation by the Phosphor Layer of High-Power White LED Emitters" IEEE Photonics Tech. Letters, vol. 25, pp. 1317-1320, 2013.

[136] Cao H, Fu J, Zhao L, Sun X, Sun B, Wang J, Li J. "Degradation behaviors and reliability of high power GaN-based white LEDs with different structures" In2016 13th China International Forum on Solid State Lighting (SSLChina), IEEE, pp. 74-79, Nov. 2016.

[137] Chen KJ, Lin BC, Chen HC, Shih MH, Wang CH, Kuo HT, Tsai HH, Kuo MY, Chien SH, Lee PT, Lin CC. "Effect of the thermal characteristics of phosphor for the conformal and remote structures in white light-emitting diodes" IEEE Photonics Journal, vol. 5, Aug 2013.

[138] A. Chakraborty, L. Shen, U.K. Mishra, "Interdigitated multipixel arrays for the fabrication of high-power light- 
emitting diodes with very low series resistances, reduced current crowding, and improved heat sinking," IEEE Trans. Electron Devices., vol. 54, pp. 1083-1090, 2007.

[139] M. Wang, H. Tao, Z. Sun, C. Zhang, 'The development and performance of the high-power LED radiator," Int. J. Therm. Sci., vol. 113, pp. 65-72, 2017.

[140] Y. Peng, R. Li, H. Cheng, Z. Chen, M. Chen, "Highpower white LED packaging using phosphor-in-glass and its thermal reliability,' 2016 13th China International Forum on Solid State Lighting (SSLChina), pp. 17-19, 2016.

[141] H. Yang, M. Wu, L. Li, D. Teng, L. Liu, G. Wang, "Improving thermal management in high power LEDs through fabricating nano-twinned copper substrates," 16th Int. Conf. Electron. Packag. Technol. ICEPT 2015, pp. 424-428, 2015.

[142] L. Yuan, S. Liu, M. Chen, X. Luo, "Thermal analysis of high power LED array packaging with microChannel cooler," 2006 7th Int. Conf. Electron. Packag. Technol. ICEPT '06, 2007.

[143] M. Ding, Y. Zhang, J. Xu, D. Zhao, H. Huang, X. Xu, Z. Miao, P. He, Y. Wang, Y. Dong, B. Zhang, "High-power single-chip GaN-based white LED with 3058 lm," Electronics Letters, vol. 52, pp. 2050-2051, 2016.

[144] C.C. Tsai, C.H. Chung, J. Wang, W.C. Cheng, M.H. Chen, Liou JS, Chang JK, Hsu YC, Hung SC, Lee CW, H.L. Hu, "High thermal stability of high-power phosphor based white-light-emitting diodes employing Ce: YAG-doped glass," In Electronic Components and Technology Conference (ECTC), pp. 700-703, 2010.

[145] Fan J, Yung KC, Pecht M. "Lifetime estimation of highpower white LED using degradation-data-driven method", IEEE Trans. Device and Mat. Rel., vol. 2, pp. 470-477, Mar. 2012.

[146] Chen Z, Hou C, Zhang Q, Li Y, Wang H. "Reinforced heat dissipation by simple graphene coating for phosphor-in-glass applied in high-power LED". Journal of Alloys and Compounds, vol. 774, pp. 954-961, Feb. 2019.

[147] Withers F, Del Pozo-Zamudio O, Mishchenko A, Rooney AP, Gholinia A, Watanabe K, Taniguchi T, Haigh SJ, Geim AK, Tartakovskii AI, Novoselov KS. "Lightemitting diodes by band-structure engineering in van der Waals heterostructures", Nature materials, vol. 14, pp. 301-306, Mar. 2015.

[148] Kim YD, Gao Y, Shiue RJ, Wang L, Aslan OB, Bae MH, Kim H, Seo D, Choi HJ, Kim SH, Nemilentsau A. "Ultrafast graphene light emitters", Nano letters, vol. 18, pp. 934-40, Jan 2018.

[149] Kim, Y. D., Kim, H., Cho, Y., Ryoo, J. H., Park, C. H., Kim, et al. "Bright visible light emission from graphene" Nature nanotechnology, vol. 10, pp. 676-681, 2015.

[150] Dobusch L, Schuler S, Perebeinos V, Mueller T. "Thermal light emission from monolayer MoS2", Advanced Materials. vol. 29, Aug 2017.

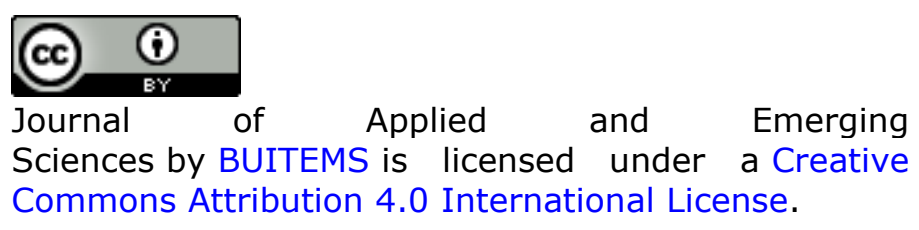

